\title{
Preparation and Pharmaco-Mechanical Characterization of Ketoprofen- Polyvinyl Alcohol Cryogel for Medical Applications
}

\author{
MONICA ILIUTA STAMATE ${ }^{1}$, LACRAMIOARA OCHIUZ²*, DANIEL TIMOFTE²*, BOGDAN CIUNTU²*, CRISTINA GHICIUC², \\ SIMONA GHERMAN ${ }^{1}$, ALINA STEFANACHE ${ }^{1}$, CIPRIAN STAMATE ${ }^{3}$ \\ ${ }^{1}$ Grigore T. Popa University of Medicine and Pharmacy, Faculty of Pharmacy, 16 Universitatii Str., 700115, lasi, Romania \\ ${ }^{2}$ Grigore T. Popa University of Medicine and Pharmacy, Faculty of Medicine, 16 Universitatii Str., 700115, lasi, Romania \\ ${ }^{3}$ Gheorghe Asachi Technical University, Faculty of Mechanics, 67 Dimitrie Mangeron Blvd., 700050, Iasi, Romania
}

\begin{abstract}
Polyvinyl alcohol is a biocompatible polymer used very commonly both in pharmaceutical and medical fields. Being a water-soluble polymer, it is suitable for the manufacture of hydrogels as well as cryogels used for various medical applications. The present work describes the preparation, structural and physicomechanical characterization of polyvinyl alcohol cryogels loaded with ketoprofen. By cryogenic technique the polymeric solutions are transformed under certain conditions into porous, elastic and very compressible structures. They are able to absorb a large amount of liquids that they give off by gentle compression. The prepared cryogels were evaluated for different physical, chemical and structural properties, as following: internal morphology, equilibrium swelling ratio and mechanical testing. The cryogel structures show good elasticity and optimal swelling at different temperatures. Due to these properties the studied cryogels are suitable for use in various medical applications involving liquid absorption, mechanical resistance and antiinflammatory effect.
\end{abstract}

Keywords: cryogels, structure, tensile strength, swelling

Polyvinyl alcohol (PVA) is a synthetic polymer with linear structure produced by free radical polymerization of vinyl acetate to Poly (Vinyl Acetate) followed by its hydrolysis. The structural properties of these polymers depend on the degree of polymerization and the percentage of hydrolysis. Compared with any other polymers, PVA exhibits superior tensile strength, more flexibility and hardness [1, 2]. During the first half of the 20th century worldwide the polyvinyl alcohol has been applied in many sectors of industry, medicine and food packaging materials [3-6]. The biodegradability of PVA through hydrolysis dependents on the hydroxyl groups on the carbon atoms $[6,7]$. It is important to highlight that the hydrophilic properties depend on molecular weight and particle crystal structure, respectively $[8,9]$. PVA polymers have no color and odor, their melting point is around $180-228^{\circ} \mathrm{C}$ and display glass transition at $75-85^{\circ} \mathrm{C}$ to became rubber. Due to the similarity in physical properties with human tissues, PVA is biocompatible, non-toxic and has been used for many biomedical applications like biomaterial for natural tissue replacement, contact lenses, artificial cartilages, catheters, artificial skin, and pancreas membranes [7, 10-12]. PVA hydrogels were also studied for bio prosthetic heart valves, reconstruction of vocal cords, artificial kidney membranes for dialysis, and intervertebral disk nuclei [3, 4, 13-16].

In pharmaceutical field is used as viscosity increasing agent for ophthalmic products, lubricant for contact lens solutions, stabilizer in emulsions, transdermal patches and sustained release oral formulations considering its poorly absorption at gastrointestinal tract, and easily elimination from the body [17-20].

The PVA polymer at high molecular weight 50,000130,000 Daltons, high concentration $10-20 \%$ and high degree of hydrolysis up to $98 \%$ can be solubilized in water at $100{ }^{\circ} \mathrm{C}$ under constant stirring in 1hour. These aqueous solutions after cooling and degassetion can be cryogelled under freezing-thawing conditions. During the freezing period the hydroxyl groups of the adjacent polymer chains will interact to form intra and intermolecular hydrogen bonds resulting in formation of crystallites [21-25]. Parameters that influence the cryogenic treatment are freezing, and thawing temperatures, and the number of cycles [13, 26-30]. In the course of cryogelation, the PVA solution in water is converted from liquid to a solid state. The composition of the polymer during these transitions would determine the viscoelastic properties of these cryogels.

Gadea etal. studied the degree of crosslinking, swelling kinetics and viscoelastic properties of cryogels and they found that the degree of cross linking and viscoelastic properties increased with increasing of freeze-thaw cycles number [2].

Omidian et al. studied the use of PVA cryogelation to enhancing mechanical properties of super porous hydrogels for gastric retention drug delivery applications, followed by several cycles of freezing and thawing [1] .

Taking into consideration their biocompatibility, drug compatibility, water solubility, film forming, good mechanical and swelling properties, the PVA cryogels have been studied as drug delivery systems in oral, transdermal, buccal, intramuscular, rectal routes of administration [23, $24,27,28]$. Degree of crystallinity plays a major role in controlling diffusion of the drug from cryogels which can be designed as matrix or reservoir for drug delivery.

Ketoprofen (KT) is a Non-Steroidal Anti-inflammatory Drug (NSAID) indicated in symptomatic therapy of painful and inflammatory processes of different origin, including: rheumatoid arthritis and periarthritis, ankylosing spondylitis (Bekhterev's disease), psoriatic arthritis, reactive arthritis (Reuters syndrome), osteoarthritis of differentlocalization, tendinitis, bursitis, myalgia, neuralgia, radiculitis, injuries of the musculoskeletal system (including sports), bruising of muscles and ligaments, sprains, rupture of ligaments and tendons of muscles. Ketoprofen inhibits cyclooxygenase, inhibits the activity of lipoxygenase and bradykinin, stabilizes lysosomal membranes and prevents

* email: lacramioara.ochiuz@umfiasi.ro; dantimofte@yahoo.com; bogdanmciuntu@yahoo.com 


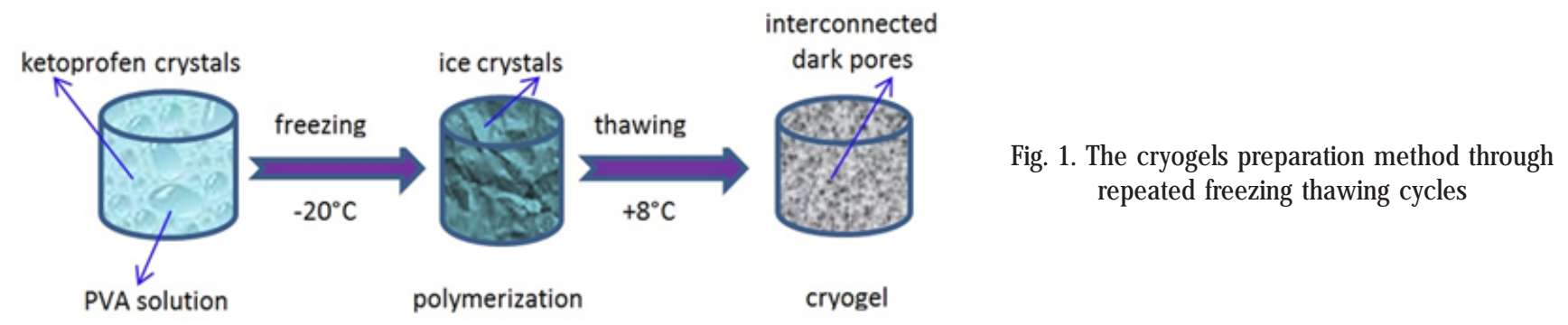

the release of enzymes involved in the inflammatory process $[5,14,31]$.

The main pharmacological uses of Ketoprofen are analgesic, anti-inflammatory and anti-edema effect. Ketoprofen has no side effects on the condition of articular cartilage. Ketoprofen is absorbed very slowly and practically does not cumulate in the body when applied locally in the form of gel. It penetrates into subcutaneous tissue, ligaments and muscles, synovial fluid and reaches therapeutic local concentrations [32].

The concentration of the drug in plasma is extremely low $[6,14,31,33-35]$. Among conventional NSAIDs, such as diclofenac, ibuprofen or indomethacin, ketoprofen is classified as an ideal candidate for percutaneous delivery due to its physicochemical and pharmacokinetic parameters. Nevertheless, ketoprofen is known for its gastrointestinal side effects, low plasma half-life, about 2 $\mathrm{h}$, molecular weight $254.3 \mathrm{~g} / \mathrm{mol}$, partition coefficient ( $\mathrm{Log}$ P) of 3.2 and high skin permeability coefficient in value of $5.01 \times 103 \mathrm{~cm} / \mathrm{h}[5,14,34]$. However, the barrier function of the skin limits ketoprofen delivery to deeper skin layers and disables its pharmacological effect at the inflammation site $[5,14]$.

Considering all this information it is desirable to develop a prolonged release pharmaceutical dosage form intended for topical administration of ketoprofen, in order to enhance its therapeutic effects and patients' compliance.

\section{Experimental part}

Materials and methods

Drug and chemicals

Polyvinyl alcohol was obtained from Chengdu Kelong Chemical Reagent Factory (Chengdu, China), and Ketoprofen $99.5 \%$ purity was received as gift from Bidachem (Fornovo San Giovanni BG, Italy). Hydrochloric acid (32\%) was purchased from Chemical Company (Romania). Disodium phosphate and sodium hydroxid were purched from Sigma Aldrich Company, Germany. Deionized water used throughout the experiments was prepared with an ELGA purelab water system. All reagents were used without further purification.

\section{Preparation of the cryogels}

Bioavailability of widely marketed ketoprofen gel is about $2.5 \%$ but Ketoprofen has a low absorption through the skin and this concentration is not sufficient, requiring successive gel applications as well as oral administration of the drug. For this reason, a higher concentration of ketoprofen ( $5 \% \mathrm{w} / \mathrm{w}$ ) was chosen in this study for an optimal therapeutic effect. The PVA-ketoprofen cryogels were prepared by a cryogelation technique (fig. 1) using a $10 \%(\mathrm{w} / \mathrm{v})$ PVA solution and $5 \%$ (w/w) ketoprofen. The PVA solution was prepared by dissolution of $10 \mathrm{~g}$ of PVA into $100 \mathrm{~mL}$ distilled water at $90^{\circ} \mathrm{C}$ on a heated water bath under stirring conditions, at $600 \mathrm{rpm}$ [3]. After 1 hour the PVA was completely dissolved and the solution was cooled to room temperature with constantstirring. The preparation of KT cryogels based on PVA was achieved by dispersion

of drug substance into PVA gels following two work procedures. The first formulation, named in this study, cryogel I, was prepared by dispersing Ketoprofen in the 10 $\%$ PVA gel at room temperature by magnetic stirring at 300 rpm for 1 hour. The second formulation, named cryogel II, was prepared by dispersing Ketoprofen in the $10 \%$ PVA gel at $90^{\circ} \mathrm{C}$ by magnetic stirring at $300 \mathrm{rpm}$ for $1 \mathrm{~h}$. This method we considered to be the hot dispersion of KT, and we selected the working temperature of $90^{\circ} \mathrm{C}$, taking into account the KT melting point of $94^{\circ} \mathrm{C}$ [36-39]. The obtained gels were degassed by ultrasonication using Bransonic ${ }^{\circledR} \mathrm{CPXH}$ digital bath, for $30 \mathrm{~min}$. The solutions obtained were poured into Petri dishes and then frozen at$20{ }^{\circ} \mathrm{C}$ for $12 \mathrm{~h}$. The frozen solutions were thawed at a constant temperature of $+8{ }^{\circ} \mathrm{C}$ in refrigerators for another 12 hours. The freeze-thaw cycle was repeated 4 times and the resulting cryogels were dried at room temperature for $12 \mathrm{~h}$, as shown in figure 1.

\section{Structural characterization of the cryogels}

The morphology of porous cryogels has been studied by Scanning Electronic Microscopy. The freeze-dried cryogel slices were sectioned to a thickness of $1 \mathrm{~mm}$, mounted on a sample holder and examined by scanning electron microscopy (SEM, quanta 3d) operated at high vacuum at $20 \mathrm{kV}[3,40]$.

Particle and pore size analysis was performed using the AutoCAD program that combines microscopic and computerized imaging techniques. The process involves importing SEM microscopic images into AutoCAD analysis program that individualizes particles and pores and then automatically calculates their dimensions.

\section{Physico-mechanical properties \\ Thickness}

For measuring cryogel thickness, five points at random using a digital micrometer were collected. Each was recorded twice to obtain the average $[25,38]$.

\section{The strain-stress mechanical properties}

The tensile strength and elongation at break were recorded using a mechanical tester device (CETR Umt-2 with labview software and load cell). The samples of cryogels ( $1 \times 3 \mathrm{~cm}^{2}$ tested sections) were held between two clamps at a distance of $3 \mathrm{~cm}$. During measurements, the cryogel was pulled by top clamp with a speed of $\mathrm{mm} /$ $\mathrm{min}$. The corresponding value on the instrument was then set to get the test data. The tensile strength of the samples was calculated using the following equation (1):

$$
\mathrm{T}_{\mathrm{S}}=\mathrm{F} / \mathrm{S} \text {, }
$$

where: $\mathrm{T}_{\mathrm{s}}$-Tensile strenght $\left(\mathrm{N} / \mathrm{mm}^{2}\right)$; F-breaking force $(\mathrm{N})$; S-sectional area of sample $\left(\mathrm{mm}^{2}\right)$.

Elongation at break (\%) is expressed by the increasing in length at breaking point reported to original length. This parameter was calculated using the equation (2):

$$
E(\%)=\left[\left(L-L_{0}\right) / L\right] .100 \text {, }
$$


where: $\mathrm{E}$ - elongation at break, $(\%) ; \mathrm{L}$ - length of the cryogel breaking $(\mathrm{mm}) ; \mathrm{L}_{0}$ - original length of cryogels $(\mathrm{mm})$.

This parameter varies in proportion to the applied traction force and inversely proportional to the sample surface [25] . This mechanical parameter was assessed both on the dry cryogels and the hydrated cryogels.

\section{Determination of the swelling degree}

The swelling ratio of cryogel samples was measured by gravimetric method at different values of temperature as following: $20,25,30,35$ and $37^{\circ} \mathrm{C}$ (the last value simulates phisiological conditions from the human body, while the first three temperature values are relevant for storage conditions during the shelf-life of a pharmaceutical product). Dry cryogel samples $\left(2 \times 2 \mathrm{~cm}^{2}\right)$ were immersed into distilled water. Swollen cryogels samples were removed, the excess water was absorbed with filter paper and then these were weighed on the electronic balance. The swelling degree $\mathrm{S}$ was calculated as (3) follows [33, 39, 41]:

$$
S(\%)=\left[\left(W_{S}-W_{D}\right) / W_{S}\right] \times 100,
$$

where: S- swelling ratio, (\%); Ws - the weight of the swollen sample at equilibrium state $(\mathrm{mg})$ and $\mathrm{Wd}$ - the weight of the dry sample $(\mathrm{mg})$.

\section{Results and discussions}

Morphological and microstructural properties

The obtained cryogels are opaque, sponge-like and elastic. The morphology of the cryogel I is presented in (fig. 2). The addition of the ketoprofen into the cold polymer solution leads to the formation of a cryogel with numerous large pores interposed with the crystalline particles of the drug, clearly presented in figure 2 .

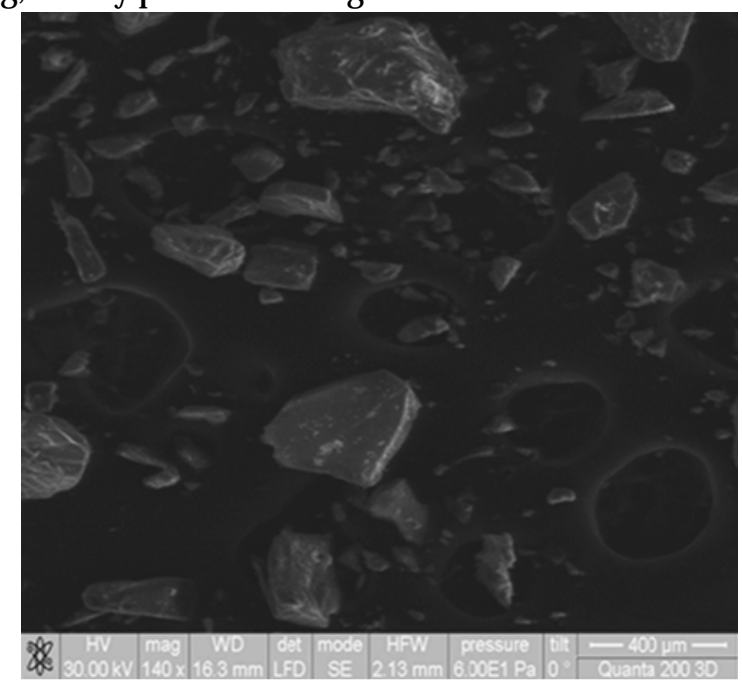

Fig. 2. SEM image of PVA ketoprofen cryogel I formula

The microscopic image of cryogel I shows a relatively uniform distribution of medium, large and small ketoprofen particles among large pores. Few small particles are cantonized in the pores of the structure. This is due to the cold dispersion of the drug in the polymer solution. The drug particles having the long crystalline structure confer rigidity to the polymer and then the pores will form in the particle-free or small-neighboring areas thathave increased elasticity and allow their formation.
The scanning electron microscopy of cryogel II revealed that this sample has typical microporous structure (fig. 3) more uniform distributed compared with cryogel I prepared at room temperature, with numerous small particles of KT dispersed in the cryogel matrix and inside the pores due to the advanced dispersion of ketoprofen at temperature of $90^{\circ} \mathrm{C}$.

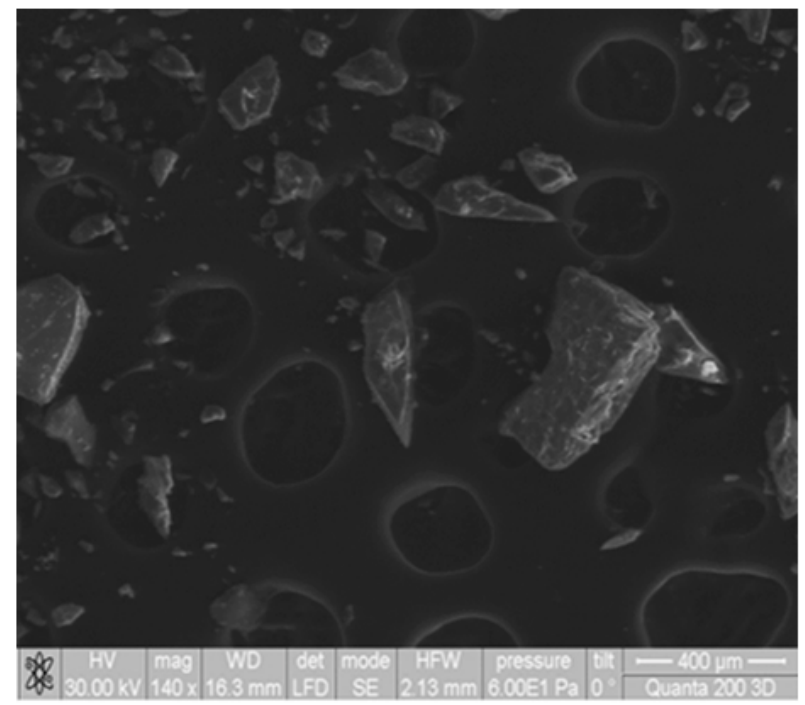

Fig. 3. SEM image of PVA ketoprofen cryogel II formula

Also, it is noted that the incorporation of ketoprofen into the hotpolymer solution leads to high dispersion degree of ketoprofen and consequently to the formation of a cryogel with smaller pores interposed with a few number of crystalline particles.

This confirms that the added crystalline drug in polymer solution at different temperatures affects the porosity percentage as it is increased with increasing temperature affecting the average pore diameter and the array of the internal microstructure (table 1). The prepared cryogels showed a microporous structure with porosity in average of $85-87 \%$ and the pore size ranging among $149-165 \mu \mathrm{m}$.

Table 1

POROSITY AND PORE DIAMETER OF KETOPROFEN CRYOGELS

\begin{tabular}{|c|c|c|}
\hline Sample name & $\begin{array}{c}\text { Pore Diameter } \\
(\mu \mathrm{m})\end{array}$ & $\begin{array}{c}\text { Porosity } \\
(\%)\end{array}$ \\
\hline PVA Ketoprofen cryogelI & $165 \pm 1.82$ & $85.67 \pm 0.59$ \\
\hline PVA Ketopren cryogel II & $149 \pm 0.14$ & $87.42 \pm 0.26$ \\
\hline
\end{tabular}

\section{Mechanical properties}

The tensile strength specific to the dry cryogels was found to be $0.705\left[\mathrm{~N} / \mathrm{mm}^{2}\right]$ for cryogel II and 0.727 [N/ $\mathrm{mm}^{2}$ ] for cryogel I, respectively when a force of $20 \mathrm{~N}$ was applied. From the results obtained at various applied forces ranging from $5 \mathrm{~N}$ to $20 \mathrm{~N}$, it can be concluded that as viscosity increases the tensile strength parameter increases, as well. Due to the presence of a large number of drug particles in cryogel I, the viscosity of the polymer is higher when tensile strength is higher. In the case of cryogel II the number of drug particles is lower and then the viscosity of the polymer is lower and the tensile strength will be lower. Table 2 lists the recorded values of cryogels tensile strength.

\begin{tabular}{|c|c|c|c|c|c|}
\hline Parameter & \multicolumn{5}{|c|}{ Values } \\
\hline Force $[\mathrm{N}]$ & 5 & 10 & 15 & 18 & 20 \\
\hline Tensile strength cryogel I $\left[\mathrm{N} / \mathrm{mm}^{2}\right]$ & 0.187 & 0.373 & 0.550 & 0.656 & 0.727 \\
\hline $\begin{array}{l}\text { Tensile strength cryogel II } \\
{\left[\mathrm{N} / \mathrm{mm}^{2}\right]}\end{array}$ & 0.167 & 0.351 & 0.530 & 0.632 & 0.705 \\
\hline
\end{tabular}

Table 2

THE TENSILE STRENGTH OF CRYOGELS RECORDED ON VARIOUS APPLIED FORCES 
The tensile strength exhibits the mechanical strength of pharmaceutical dosage form, in our case of cryogels, againstunusual deformation during the storage and topical application.

The elongation expressed as percentages (\%) depends on the hydrogen bonding of polymer molecule to water molecule, as well. As the lower viscosity polymer shows more elongation [42]. The elongation break for cryogel II in dry state is $25 \%$ and in hydrated state is 30\%, while for the cryogel I in dry state this parameter is $12 \%$ and in hydrated state is $18 \%$, respectively.

In the dry state, the cryogel II is more elastic then the cryogel I, due to the presence in its structure of small crystalline particles of ketoprofen which do not resist to elongation. After hydration both cryogels became more elastic, due to the pore fluid and soft structure.

\section{Swelling degree}

When the cryogel pieces were immersed in water, they moistened within 1-2 s maintaining their original shape. Growing surface of cryogels entirely depends on the porosity of polymer matrix. In the case of cryogel I, water absorption is lower because of the uneven pore structure and size as well as large-scale drug crystals which inhibit the expansion of the polymer matrix (fig. 4).

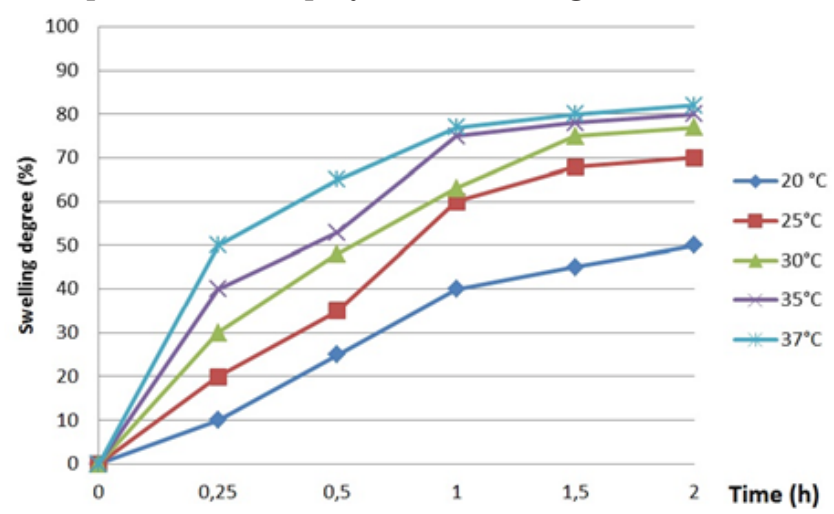

Fig. 4. The swelling degree of cryogel I recorded at various temperatures

In the case of cryogel II, water absorption exceeds 90 $\%$, at $37^{\circ} \mathrm{C}$ due to size and shape of cryogel pores. Moreover, the small crystals of the drug allow the passage of fluid through the pores and the hydration of the polymer matrix (fig. 5).

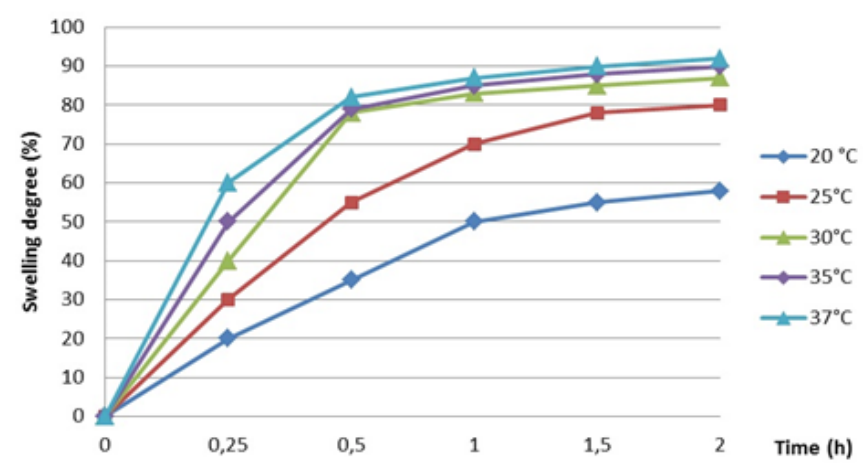

Fig. 5. The swelling degree of cryogel II recorded at various temperatures

Thus, the data we presented here could have a wide range of applications in the literature and for a multitude of patients [43], considering also our previous work in the pharmacological [44, 45], toxicological [46], biochemical [47] or molecular [48] context.

\section{Conclusions}

The cryogels based on polyvinyl alcohol loaded with ketoprofen were developed in order to obtain a prolonged release pharmaceutical product intended for topical application.

The cryogel formula prepared by the dispersion of ketoprofen in the cold polymer solution (cryogel I) exhibited large drug crystalline particles in its structure, having lower mechanical properties compared to cryogel II.

The crystalline nature of the drug particles and their size modify the formation of the pores in the cryogels structure, both as spatial distribution and as shape. Cryogel I, containing a large number of crystalline drug particles, presents fewer pores in large sizes. In the case of cryogel II, the addition of ketoprofen into the hot polymer leads to an advanced dispersion of drug substance, resulting a better structured cryogel with small crystalline particles dispersed predominantly in the pores of the matrix.

The elasticity of cryogel II is higher compared to cryogel I, due to the fact that small drug particles allow the elongation and relaxation of the polymer, moving along with it in the direction of movement.

The swelling evaluation of cryogels revealed that they have good mechanical properties and water absorption that allows the gradual release of the drug as the polymer matrix becomes hydrated and the soft structure of the polymer chains relaxes.

\section{References}

1.OMIDIAN, H., PARK, K., J. Drug Deliv. Sci. Technol., 18, no. 2, 2008, p. 83.

2.GADEA, J.L., CESTEROS, L.C., KATIME, I., European Polymer J ournal, 49, 2013, p. 3582.

3.STAMATE, CRETAN, M., STAMATE, C., Solid State Phenomena, 216, 2014, p. 205.

4.BAKER, M.I. et al, J ournal of Biomedical Materials Research Part B: Applied Biomaterials, 100, no. 5, 2012, p. 1451.

5.BIRMINGHAM, B., BUVANENDRAN, A., Nonsteroidal Anti-inflammatory Drugs, Acetaminophen, and COX-2 Inhibitors, in Practical Management of Pain, Fifth Edition., 2014, pp. 553-568.

6.HERSH, E.V., DIONNE, R.A., MOORE, P.A., Compendium, 38, 2017, p. 74.

7.KAITY, S., ISAAC, J., GHOSH, A., Carbohydr Polym., 94, 2013, p. 456. 8.SAMEER, J., KOMAL, V., SHREE, R.S., Biomed. J. Sci. \& Tech. Res., 5, no. 1, 2018, p. 1.

9.GHEBAUR, A., GAREA, S.A., IOVU, H., Int. J. Pharm., 436, 2012, p. 568.

10.HIMI, M., MAURYA, S.D., J ournal of Drug Delivery \& Therapeutics. 3, no. 2, 2013, p. 131.

11.WAN, W.K., CAMPBELL, G., ZHANG, Z.F., HUI, A.J., BOUGHNER, D.R., J. Biomed. Mater. Res., 63, 2002, p. 854.

12.KAMOUN, E.A., CHEN, X., MOHY, M.S., El-REFAIE, E., KENAWY, S., Arabian Journal of Chemistry, 8, no. 1, 2015, p. 1.

13.CRISPIM, E. et al, Express. Polym. Lett., 6, no. 5, 2012, p. 383.

14.RENCBER, S., KARAVANA, S. Y., OZYAZICI, M., J. Pharm. Sci., 34, 2009, p. 203.

15.BHOYAR, N.T.K., ALEXANDER, A., J ournal of Sciences and Allied Health Sciences, 2, 2012, p. 21.

16.VASHIST, A. et al, Journal of Materials Chemistry B., 2, no. 2, 2014, p. 147.

17.VASHIST, A., AHMAD, S., Oriental J ournal of Chemistry, 29, no. 3, 2013, p. 861.

18.HALAKE, $\mathrm{K}$. et al, J ournal of Industrial and Engineering Chemistry, 20, no. 6, 2014, p. 3913.

19.QIU, K., NETRAVALI, A.N., J. Polym. Environ., 21, 2013, p. 658.

20.MISHRA, B., UPADHYAY, M., REDDY, ADENA, S.K., VASANT, B.G., MUTHU, M.S., Austin J. Biomed. Eng., 4, no. 1, 2017, p. 1037.

21.ALBDIRY, M.T., YOUSIF, B.F., Mater Des., 48, 2013, p. 68. 
22.BUCIUMAN, C., MARIAN, E., TITA, B., JURCA, T., CHIS, A., VICAS, L., Rev. Chim. (Bucharest), 69, no. 11, 2018, p. 3221.

23.IPATE, A. M., HAMCIUC, C., KALACHEV, Y., GHERMAN, S., OCHIUZ, L., J ournal of Drug Delivery Science and Technology, 44, 2018, p. 505. 24.KENAWY, E.R., KAMOUN, E.A., ELDIN, M.S., EL-MELIGYA, M.A., Arab J. Chem., 7, 2014, p. 372.

25.KAITY, S., ISAAC, J., GHOSH, A., Carbohydr Polym., 94, 2013, p. 456. 26.DAS, N., International J ournal of Pharmacy and Pharmaceutical Sciences, 5, 2013, p. 112.

27.VASHIST, A. et al, J ournal of Materials Chemistry B. 2(2), 2014, p. 147-166.

28.SHUAI, C., MAO, Z, LU, H., NIE, Y., HU, H., PENG, S., Fabrication of porous polyvinyl alcohol scaffold for bone tissue engineering via selective laser sintering. Biofabrication, ;5, no. 1, 2013, Article no. 015014.

29.SWAPNA, V.P., SELVIN, T.P., SURESH, K.I., SARANYA, V., RAHANA, M.P., RANIMOL, S., Thermal properties of poly (vinyl alcohol) (PVA)/ halloysite nanotubes reinforced nanocomposites, Int. J. Plast. Technol., 19, no. 1, 2015, p. 124.

30.WANG, J., WANG, X., XU, C., ZHANG, M., ZHANG, X., Polym Int., 60, 2011, p. 816

31.HANSON, P.D., MADDISON, J.E., Chapter 13 - Nonsteroidal antiinflammatory drugs and chondroprotective agents, in Small Animal Clinical Pharmacology, Second Edition., 2008, p. 286-308.

32.CIOCAN PENDEFUNDA, A. A., LEATA, R., NICOLAE, V., ANCUTA, C., CRACIUN, A., E., CERGHIZAN, D., IORDACHE, C., Rev. Chim. (Bucharest), 69, no. 7, 2018, p. 1779.

33.NG, K.W., WANIVENHAUS, F., CHEN, T., HSU, H.C., ALLON, A.A., ABRAMS, V.D., TORZILLI, P.A., WARREN, R.F., MAHER, S.A., Tissue Eng., 18, 2012, p. 1273.

34.LATIF, I., AL-ABODI, E.E., BADRI, D.H., AL KHAFAGI, J., American Journal of Polymer Science, 2, no. 6, 2012, p. 135.

35.LATIF, I., ALWAN, T.B., AL-DUJAILI, A.H., Nanoscience and Nanotechnology, 2, no. 6, 2012, p. 190.
36.ABDOU, H.M., HANNA, S., MUHAMMAD, N., Dissolution. In: GENNARO, A. R. Remington: The Science and Practice of Pharmacy, University of Science Philadelphia. 2000, pp. 654-699.

37.PATEL, B., SHAH, C., Indo Am. J. P. Sci., 3, no. 9, 2016, p. 960.

38.GROSSER, T., SMYTH, E., FITZ, GERALD, G.A., Anti-inflammatory, antipyretic and analgesic agents; pharmacoterapy of gout, in: SHANAHAN, J.F., NAGLIERI, C. (Eds.), Goodman Gilman's: The Pharmacol. Basis Ther. 12th ed.; China Translation \& Printing Services, Ltd., China, 2011.

39.KANTOR, T.G., Pharmacoterapy, 6, 1986, p. 93.

40.RAMA, SUBBA, REDDY, P. ESWARAMMA, S., KRISHNA, RAO, K.S.V., ILL LEE, Y., Bull Korean Chem Soc., 35, no. 8, 2014, p. 2391.

41.MAJ I, P., GANDHI, A., J ANA, S., MAJ I, N., J ournal of PharmaSciTech, 2(2), 2013, p. 62.

42.VERGNAUD, J.M., ROSCA, I.D., Assessing Bioavailability of Drug Delivery Systems. Taylor \& Francis Group, LLC, United States of America, 2005, pp. 74-75.

43.CIOBICA, A., PADURARIU, M., CIOBICA, A., TIMOFTE, D., STEFANESCU, C., NASREDDINE, Z., International J ournal of Geriatric Psychiatry, 32, no. 1, 2017, p. 116.

44.OCHIUZ, L., GRIGORAS, C., POPA, M., STOLERIU, I., MUNTEANU, C., TIMOFTE, D., PROFIRE, L., GRIGORAS, A.G., Molecules, 21, no 7, 2016, p. 858.

45.GRADINARU, I., TIMOFTE, D., VASINCU, D., TELSOIANU, D., CIMPOESU, R., MANOLE, V., GHEUCA-SOLOVASTRU, L., Mat. Plast., 51. no 3, 2014, p. 230.

46.DUMBRAVA, D., RADU, C., IOV, T., DAMIAN, S., SANDU, I., TIMOFTE, D., CHIROBAN, O., Rev. Chim. (Bucharest), 69, no. 7, 2018, p. 1889. 47.TROFIN, F., CIOBICA, A., HONCERIU, C., COJOCARU, S., STOICA, B., COJOCARU, D., CIORNEA, E., TIMOFTE, D., Romanian Biotechnological Letters, 22, no. 2, 2017, p. 12439.

48.AURSULESEI, V., VASINCU, D., TIMOFTE, D., VRAJ ITORIU, L., GATU, I., IACOB, D., GHIZDOVAT, V., BUZEA, C., AGOP, M., General Physiology and Biophysics, 35, no 3, 2016, p. 287.

Manuscript received: 13.08 .2018 